\title{
Ultrasound-guided totally implantable venous access ports via the right innominate vein: a new approach for patients with breast cancer
}

\author{
Liang $X u^{1+}$, Wenming Qin ${ }^{2 \dagger}$, Weiwei Zheng ${ }^{3^{*}}$ (D) and Xingwei Sun ${ }^{4^{*}}$
}

\begin{abstract}
Background: To evaluate the feasibility and safety of ultrasound-guided totally implantable venous access port (TIVAP) implantation via the right innominate vein in patients with breast cancer.

Methods: Sixty-seven breast cancer patients underwent ultrasound-guided implantation of TIVAPs via the right innominate vein for administration of chemotherapy. Clinical data including technical success, success rate for the first attempt, periprocedural, and postoperative complications were recorded and retrospectively studied.

Results: All patients underwent successful surgery. The success rate of the first attempt was $95.52 \%$ (64/67). The operation time was 28 to $45 \mathrm{~min}$, with an average of $36 \pm 6 \mathrm{~min}$. Periprocedural complications included artery punctures in $1(1.50 \%, 1 / 67)$ patient. Prior to this study, the mean TIVAP time was $257 \pm 3$ days (range 41 to 705 days). The rate of postoperative complications was 4.48\% (3/67), including catheter-related infections in 1 case and fibrin sheath formation in 2 cases. Up to the present study, three people had unplanned port withdrawal due to complications, and the TIVAPs for 25 patients were still in normal use.

Conclusions: The success rate of ultrasound-guided TIVAPs via the right innominate vein is high with low complications, thus safe and feasible. This technique can provide a new option for chemotherapy of breast cancer patients.
\end{abstract}

Keywords: Totally implantable venous access ports, Ultrasound-guided, Innominate vein, Complications, Breast cancer

\section{Background}

Totally implantable venous access ports (TIVAPs) can be used for the infusion of various chemotherapeutic drugs [1]. Compared with peripherally inserted central catheters (PICCs), TIVAPs are widely used in the clinic because of their advantages of more convenient care and lower rate of complications [2]. Currently, the application of TIVAPs through either the internal jugular vein

\footnotetext{
* Correspondence: sdfeysxw@163.com; zhengweiweidoctor@163.com ${ }^{\dagger}$ Liang Xu and Wenming Qin contributed equally to this work.

${ }^{4}$ Department of Intervention, The Second Affiliated Hospital of Soochow University, Suzhou 215004, Jiangsu, China

${ }^{3}$ Department of Orthopaedics, Affiliated Suzhou Hospital of Nanjing Medical

University, Suzhou 215004, Jiangsu, China

Full list of author information is available at the end of the article
}

(IJV) or subclavian vein (SCV) or cephalic vein surgical cutdown approach is the most widely used $[3,4]$.

Recently, ultrasound-guided central vena catheterization (CVC) via the innominate vein (INV) has been suggested as an alternative approach to IJV. It is safe and reliable both in infants and adults [5-9]. However, the INV approach is rarely reported for TIVAPs, specifically in breast cancer patients, and it is still overlooked [10].

To evaluate the feasibility and safety of this new approach for TIVAPs, clinical data of patients receiving TIVAPs via the right INV for chemotherapy were collected and retrospectively analyzed.

(c) The Author(s). 2019 Open Access This article is distributed under the terms of the Creative Commons Attribution 4.0 International License (http://creativecommons.org/licenses/by/4.0/), which permits unrestricted use, distribution, and 


\section{Methods}

\section{Patients}

Clinical and nursing data for 67 adult patients with left breast cancer who underwent implantations of TIVAPs via the right INV from January 2017 to January 2018 were collected (Table 1). The TIVAP used was purchased from B. Braun (B. Braun, 04436946 6.5F, FR).

\section{Implantation procedures}

The study was approved by the ethics committee of the Changshu Hospital Affiliated to Nanjing University of Chinese Medicine, and all methods were performed in accordance with the relevant guidelines and regulations.

Preoperative blood routine examination and blood coagulation tests were performed. Surgery was performed in strict accordance with aseptic operation procedures, such as hand washing and disinfection during the operation.

Patients lay supine with heads turned to the left, and the surgeon stood at the right side of the patient's head with the high-frequency ultrasound probe in his left hand and the puncture needle in his right.

The ultrasound probe went down the right IJV to the superior sternoclavicular joint, showing that the right IJV and right SCV converged to form the initial part of the right INV, and there was a good view of the right subclavian artery (SCA) (beside the SCV). Then, the right INV was punctured under ultrasound guidance by in-plane technique (Fig. 1).

After the successful puncture, the introducer sheath and port catheter were introduced subsequently. A subcutaneous pocket was prepared by blunt dissection on the anterior chest wall, and the pocket was sized to just fit the port. A tunnel needle catheter traction crossed above the clavicle through the incision, and the catheter was cut in a suitable position with fluoroscopy and joined to the port.

Subsequently, the incision was sewn up and covered with a compression bandage. The infusion was verified by puncturing the port and drawing back. The correct position of the port catheter was assessed again (Fig. 2).

Clinical data including success rate for the first puncture, operation time, perioperative complications, and postoperative complications were recorded.

Specialized nurses were equipped to maintain and manage the TIVAPs after implantation, and a 10-ml

Table 1 Patients' characteristics $(N=67)$

\begin{tabular}{ll}
\hline Characteristics & $N(\%)$ \\
\hline Age (years) (mean \pm SD) & $46 \pm 11(35-63)$ \\
Female/male & $67 / 0$ \\
Body weight (kg) (mean \pm SD) & $52 \pm 16(43-79)$ \\
Height $(\mathrm{cm})($ mean \pm SD) & $163 \pm 19(150-171)$ \\
Body mass index (mean \pm SD) & $21 \pm 4(19-25)$ \\
\hline
\end{tabular}

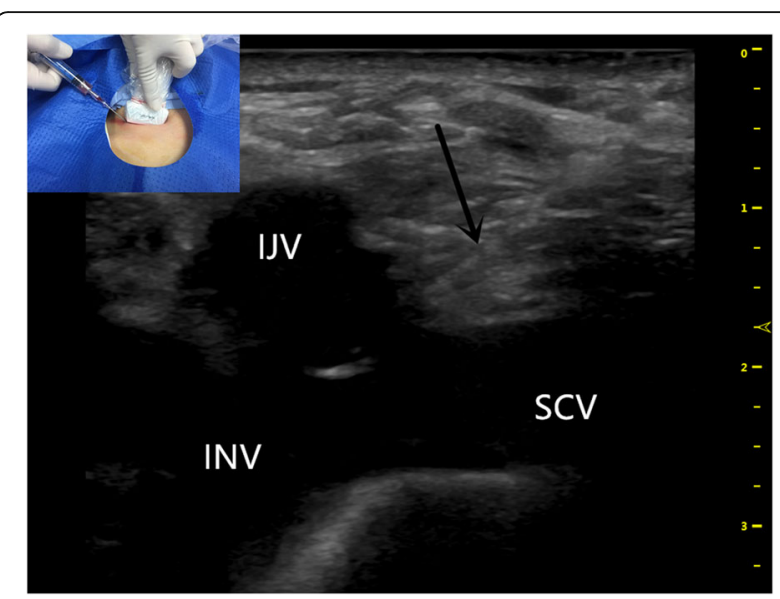

Fig. 1 Ultrasound-guided successful puncture of right INV with an inserted needle (black arrow). INV longitudinal view, in-plane approach. INV indicates innominate vein. IJV indicates internal jugular vein. SCV indicates subclavian vein

flushing tube of $50-100 \mathrm{iu} / \mathrm{ml}$ heparin saline or saline was used, not more than once every 28 days.

\section{Results}

The operation was successful in 67 cases (Table 2). The intraoperative puncture needle entered the right INV once successfully to consider the puncture successful at the first puncture. The success rate for the first puncture was $95.52 \%(64 / 67)$. The other three patients had a successful puncture at the second attempt.

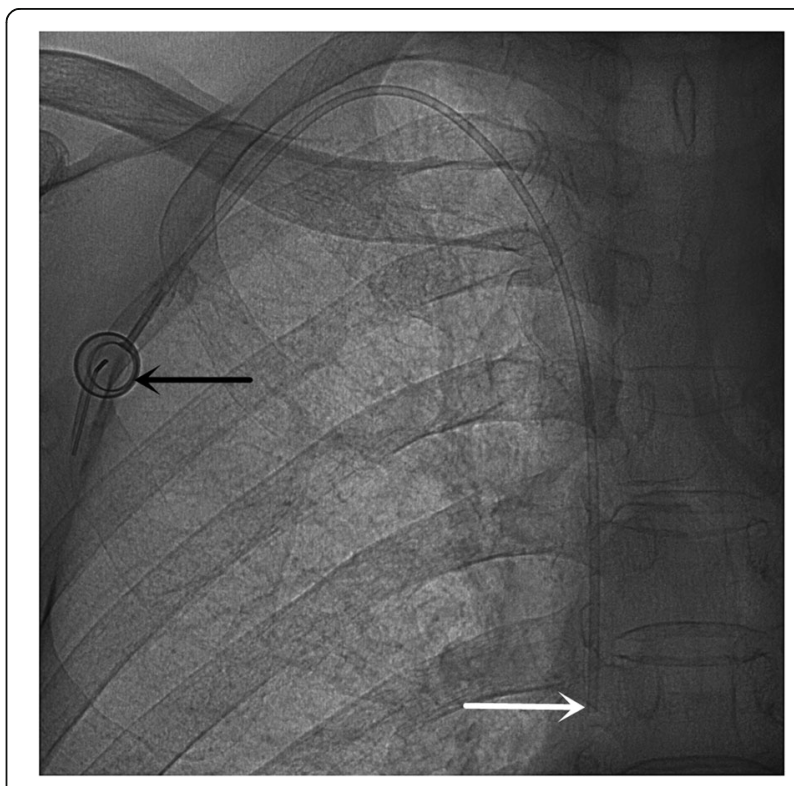

Fig. 2 TIVAP is implanted via the right INV approach, crossing over the right clavicle. The port (black arrow) is on the right chest wall, and the catheter tip (white arrow) is placed at the joint of the superior vena cava and the right atrium 
Table 2 Details of the US-guided right INV puncture for TIVADs $(N=67)$

\begin{tabular}{ll}
\hline Details & $N(\%)$ \\
\hline Success rate of surgery (\%) & $67(100)$ \\
Success rate of first attempt (\%) & $64(95.52)$ \\
Operation time (minutes) (mean \pm SD) & $36 \pm 6(28-45)$ \\
Length of catheter introduction (cm) (mean \pm SD) & $19 \pm 3(17-24)$ \\
TIVAP time (days) & $257 \pm 39(41-605)$ \\
\hline
\end{tabular}

The operation time was 28 to $45 \mathrm{~min}$, with an average of $36 \pm 6 \mathrm{~min}$. The length of the catheter was 17 to $24 \mathrm{~cm}$, with an average of $19 \pm 3 \mathrm{~cm}$. Prior to this study, the mean TIVAP time was $257 \pm 39$ days (range 41 to 605 days) (Table 2).

Perioperative complications included one case $(1.50 \%$, $1 / 67$ ), in whom the SCA was mistakenly perforated, but the second puncture was successful with no interventions. No pneumothorax or hemothorax were observed (Table 3). Postoperative complications included mean complications that occurred 2 weeks after implantation. The postoperative complications rate was 4.5\% (3/67), including catheter-related infection in 1 case and fibrin sheath formation in 2 cases. They all led to unplanned port withdrawal after failure of anti-infection or thrombolytic therapy (Table 3).

Notably, no catheter ectopic or catheter rupture occurred during the follow-up period. Twenty-five TIVAPs were still in normal use at the end of the follow-up period.

\section{Discussion}

TIVAPs are widely used in the clinic because they require no external dressing, allow patient activity, and improve the life of patients, especially in patients with breast cancer who require frequent chemotherapy and blood sampling [11]. At present, surgical cutdown of the cephalic vein and percutaneous puncture for TIVAP implantation via IJV and SCV are the most widely used for their high success rate and low complications [3, 12, 13].

However, the IJV and SCV may not be the best option for many clinical situations. The high puncture point seems to be one of the shortcomings of the IJV approach, the large angle of the fold of the catheter due to the high puncture point may lead to catheter discount,

Table 3 Incidence of intraoperative and postoperative complications and actions taken $(N=67)$

\begin{tabular}{lll}
\hline Complications & No. (\%) & Actions taken \\
\hline Artery perforated & $1(1.5)$ & Self-limited \\
Catheter-related infection & $1(1.5)$ & Antibiotics and port removal \\
Fibrin formation & $2(3.0)$ & Thrombolysis and port removal \\
Total & $4(6.0)$ & \\
\hline
\end{tabular}

clogging, and fracture [14]. Larger angle and longer catheterization pathway are important factors in the reduction of patient comfort and may cause an unattractive appearance for patients with breast cancer after TIVAP placement [15]. The puncture point of SCV approach is lower, which is more convenient and comfortable than IJV, but the occurrence of pinch-off syndrome (POS) may lead to dysfunction of the catheter. POS is the main cause of catheter rupture or fracture for the SCV approach [14].

In 1982, Niederhuber et al. of MD Anderson Cancer Center in the USA, first applied the TIVAP surgical technique to the central vein through the cephalic vein [16]. Studies showed that, compared with the SCV approach, the incidence of complications of the INV approach using surgical techniques for TIVAP is low, and it is considered superior to the SCV approach [17]. Koketsu et al. [18, 19] also believed that TIVAP could provide safe and feasible infusion channels for patients through INV, which is worthy of promotion and application. However, surgical incision and implantation of TIVAPs also have the disadvantages of long operation time, low success rate, and great trauma [20].

With the development of ultrasound technology, however, ultrasound-guided INV catheterization has been gradually applied in clinical practice, and many studies have confirmed its safety and effectiveness [5-9]. However, ultrasound-guided puncture of INV for TIVAPs is rarely reported and is still overlooked.

The IJV merges with the SCV behind the sternoclavicular joint to form the INV, and the bilateral INVs converge to form the superior vena cava (SVC). We know that the INV is relatively fixed and has a larger diameter than the IJV and SCV; this provides the possibility of ultrasound-guided puncture of INV safely and effectively [21].

In this preliminary study, the right INV approach was obtained only, as the thoracic duct afflux into the central vein is via left INV, so the right INV approach was preferred to avoid thoracic duct damage. But in Beccaria's study [9], 78 patients with left INV catheterization did not have thoracic duct injury. Another study showed that left INV catheterization was safe and feasible in children [22]. The safety and feasibility of left INV approach of TIVAPs for patients need to be studied further.

Beccaria et al. conducted a comparative study between CVC via the INV and IJV approach. The study indicates that the US-guided CVC via INV approach is safe and easy to operate, and it is a reasonable alternative to IJV approach in adults [9]. In our study, right INV approach was adopted in 67 cases, the success rate of the first puncture was $95.52 \%$ (64/67), similar to the results of $90.18 \%(257 / 285)$ reported by Beccaria et al [9] 
One study showed that the success rate of catheterization of the left INV was higher than that of the right in newborns and children [23].

In this study, the rate of perioperative complications was $1.50 \%(1 / 67)$, consisting of one case of self-limited arterial puncture, visualized as SCV by ultrasound. The second puncture was successful, and there was no hematoma formation.

The overall postoperative complication rate in this study was $4.48 \%(3 / 67)$, which was lower than that in most other studies [12, 24]. Catheter-related infections were found in 1 case 5 weeks after surgery. The blood culture showed Staphylococcus aureus. Fibrin sheath formation was found by digital subtraction angiography (DSA) in 2 cases. They all led to unplanned port withdrawal after active anti-infection and failure of thrombolytic therapy. It remained important to avoid unplanned port withdrawal by standardizing the operation and paying attention to the maintenance and management of the catheter.

Lin et al. [25] reported 2620 cases of patients with the SCV puncture route. The incidence of catheter fracture was $2.6 \%$, highlighting that POS is the main cause of catheter rupture. In this study, supraclavicular puncture of right INV was used to avoid the occurrence of POS by crossing above the clavicle, and no catheter fracture was found. In addition, none of the patients had catheter malposition after the procedure, which might be related to the fact that the range of catheter activity by INV approach was small, and the location of the catheter was accurately positioned by DSA fluoroscopy during the operation.

Given the preliminary results reported here (the study was retrospective and the cases were limited), there is a clear need for a randomized controlled study to confirm the feasibility and safety of the ultrasound-guided right INV approach for TIVAPs. It may stimulate future research in this area.

\section{Conclusions}

TIVAPs are widely used in clinical practice to avoid repeated venipuncture and increase the freedom of activity for the patient. Ultrasound-guided supraclavicular TIVAPs through the right INV approach avoid the large angle bending of catheter and POS, have a high success rate, and show low complications, thereby providing another option for patients with breast cancer.

\footnotetext{
Abbreviations

CVC: Central vena catheterization; DSA: Digital subtraction angiography; IJV: Internal jugular vein; INV: Innominate vein; PICC: Peripherally inserted central catheters; POS: Pinch-off syndrome; SCA: Subclavian artery; SCV: Subclavian vein; TIVAP: Totally implantable venous access port
}

\section{Authors' contributions}

LX and WQ carried out the studies, participated in collecting data, and drafted the manuscript. WZ analyzed data. XS helped to revise the manuscript. All authors read and approved the final manuscript.

\section{Funding}

This study was supported by the Pre-research Project of the National Natural Science Foundation of China (SDFEYGJ1801).

\section{Availability of data and materials}

Research data can be obtained from corresponding author upon reasonable request.

\section{Ethics approval and consent to participate}

The study was approved by the ethics committee of Changshu Hospital Affiliated to Nanjing University of Chinese Medicine and consent to participate from the patient was available.

Consent for publication

All authors approved the final manuscript for publication.

\section{Competing interests}

The authors declare that they have no competing interest.

\section{Author details}

${ }^{1}$ Department of General Surgery, Changshu Hospital Affiliated to Nanjing University of Chinese Medicine, Changshu 215500, Jiangsu, China. ${ }^{2}$ Department of Pain, Bazhong Central Hospital, Bazhong 636000, Sichuan, China. ${ }^{3}$ Department of Orthopaedics, Affiliated Suzhou Hospital of Nanjing Medical University, Suzhou 215004, Jiangsu, China. ${ }^{4}$ Department of Intervention, The Second Affiliated Hospital of Soochow University, Suzhou 215004, Jiangsu, China.

Received: 1 August 2019 Accepted: 15 October 2019

Published online: 25 November 2019

\section{References}

1. Marcy PY, Schiappa R, Ferrero JM, et al. Patient satisfaction and acceptance of their totally implanted central venous catheter: a French prospective multicenter study[J]. The Journal of Vascular Access. 2017;18(5):390-5.

2. Singh KR, Agarwal G, Nanda G, et al. Morbidity of chemotherapy administration and satisfaction in breast cancer patients: a comparative study of totally implantable venous access device (TIVAD) versus peripheral venous access usage[J]. World J Surg. 2014;38(5):1084-92.

3. Wu S, Huang J, Jiang $Z$, et al. Internal jugular vein versus subclavian vein as the percutaneous insertion site for totally implantable venous access devices: a meta-analysis of comparative studies.[J]. BMC Cancer. 2016;16(1):747.

4. Biffi R, Orsi F, Pozzi S, et al. Best choice of central venous insertion site for the prevention of catheter-related complications in adult patients who need cancer therapy: a randomized trial.[J]. Ann Oncol. 2009;20(5):935-40.

5. Breschan C, Graf G, Jost R, et al. Ultrasound-guided supraclavicular cannulation of the right brachiocephalic vein in small infants: a consecutive, prospective case series[J]. Pediatr Anesth. 2015;25(9):943-9.

6. Aytekin C, Özyer U, Harman A, et al. Ultrasound-guided brachiocephalic vein catheterization in infants weighing less than five kilograms.[J]. Journal of Vascular Access. 2015;16(6):512-4

7. Breschan C, Graf G, Jost R, et al. A retrospective analysis of the clinical effectiveness of supraclavicular, ultrasound-guided brachiocephalic vein cannulations in preterm infants|anesthesiology|ASA publications[J]. Anesthesiology. 2018;128(1):38-43.

8. Thompson M E. Ultrasound-guided cannulation of the brachiocephalic vein in infants and children is useful and stable[J]. Turkish Journal of Anaesthesiology \& Reanimation, 2017, 45(3):153.: 153-157.

9. Beccaria PF, et al. The brachiocephalic vein as a safe and viable alternative to internal jugular vein for central venous cannulation. Anesth Analg. 2018;1.

10. Sun X, Xu J, Xia R, et al. Efficacy and safety of ultrasound-guided totally implantable venous access ports via the right innominate vein in adult patients with cancer: single-centre experience and protocol [J]. Eur J Surg Oncol. 2019;45(2):275-8. 
11. Kreis $H$, Loehberg CR, Lux MP, et al. Patients attitudes to totally implantable venous access port systems for gynecological or breast malignancies[]]. European Journal of Surgical Oncology the Journal of the European Society of Surgical Oncology \& the British Association of Surgical Oncology. 2007;33(1):39-43.

12. Gurkan S, Seber S, Gur O, et al. Retrospective evaluation of totally implantable venous access port devices: early and late complications. J buon. 2015;20(1):338-45.

13. Zhou J, Qian S, He W, et al. Implanting totally implantable venous access port via the internal jugular vein guided by ultrasonography is feasible and safe in patients with breast cancer[J]. World Journal of Surgical Oncology. 2014;12(1):378.

14. D'Silva KJ, Dwivedi AJ, Shetty A, et al. Pinch-off syndrome: a rare complication of totally implantable venous devices[J]. Breast J. 2005:11(1):83-4.

15. Xiao SP, Xiong B, Chu J, et al. Fracture and migration of implantable venous access port catheters: cause analysis and management of 4 cases. J Huazhong Univ Sci Technolog Med Sci. 2015;35(5):763-5.

16. Niederhuber JE. Totally implanted venous and arterial access system to replace external catheters in cancer treatment[]]. Surgery. 1982;92(4):706-12.

17. Dauser B, Stopfer J, Ghaffari S, et al. Subclavian vein puncture vs. surgical cut-down to the cephalic vein for insertion of totally implantable venous access ports[]]. Eur Surg. 2012;44(5):331-5.

18. Koketsu S. Outcome of cephalic vein cut-down approach: a safe and feasible approach for totally implantable venous access device placement. [J]. Oncol Lett. 2010;1(6):1029-31.

19. Otsubo R, Hatachi T, Shibata K, et al. Evaluation of totally implantable central venous access devices with the cephalic vein cut-down approach: usefulness of preoperative ultrasonography[J]. J Surg Oncol. 2015;113(1):114-9.

20. Cavallaro G, Sanguinetti A, lorio O, et al. Ultrasound-guided vein puncture versus surgical cut-down technique in totally implantable venous access devices (TIVADS): a prospective comparative study on safety, efficacy and complications[]]. Int Surg. 2014;95(4):475-8.

21. Gurjar M, Baronia AK, Azim A, Poddar B, Kumar S, Agarwal SK, Majumdar $\mathrm{G}$. Should blind internal jugular venous catheterization be avoided in a patient with ipsilateral permanent pacemaker implant? Am J Emerg Med. 2006;24:501-2.

22. Nardo MD, Stoppa F, Marano M, et al. Ultrasound-guided left brachiocephalic vein cannulation in children with underlying bleeding disorders: a retrospective analysis.[J]. Pediatric critical care medicine : a journal of the Society of Critical Care Medicine and the World Federation of Pediatric Intensive and Critical Care Societies. 2014;15(2):44-8.

23. Breschan C, Platzer M, Jost R, et al. Ultrasound-guided supraclavicular cannulation of the brachiocephalic vein in infants: a retrospective analysis of a case series. Paediatr Anaesth. 2012;22(11):1062-7.

24. Wang YC, Lin PL, Chou WH, et al. Long-term outcomes of totally implantable venous access devices[J]. Support Care Cancer. 2017;25(7):2049-54.

25. Lin $\mathrm{CH}, \mathrm{Wu} \mathrm{HS}$, Chan DC, et al. The mechanisms of failure of totally implantable central venous access system: analysis of 73 cases with fracture of catheter[]]. Eur J Surg Oncol. 2010;36(1):1000-3.

\section{Publisher's Note}

Springer Nature remains neutral with regard to jurisdictional claims in published maps and institutional affiliations.

Ready to submit your research? Choose BMC and benefit from:

- fast, convenient online submission

- thorough peer review by experienced researchers in your field

- rapid publication on acceptance

- support for research data, including large and complex data types

- gold Open Access which fosters wider collaboration and increased citations

- maximum visibility for your research: over $100 \mathrm{M}$ website views per year

At BMC, research is always in progress.

Learn more biomedcentral.com/submissions 